\title{
Pattern of Spinal Pain Managed at the Physiotherapy Department of a Tertiary Health Institution in Nigeria
}

\author{
Odole A.C. ${ }^{1}$, Ogunlana M.O. ${ }^{2}$, Akinpelu A.O. ${ }^{1}$, Oladejo K.S. ${ }^{1}$ \\ ${ }^{1}$ Department of Physiotherapy, College of Medicine, University of Ibadan, Nigeria \\ ${ }^{2}$ Department of Physiotherapy, Federal Medical Centre, Abeokuta Ogun State, Nigeria \\ Correspondence
}

A.C. Odole, Department of Physiotherapy, College of Medicine, University of Ibadan, Nigeria • skodole@yahoo.com,adesola_odole@yahoo.com,acodole@comui.edu.ng

\begin{abstract}
Spinal pain (SP) is one of the clinical conditions managed at the orthopaedic unit of physiotherapy departments of hospitals all over the world. There is a dearth of information on the pattern of SP being managed in these departments. The aim of this study was to investigate the pattern of SP managed at the physiotherapy outpatient department of the University College Hospital, Ibadan, Nigeria.

Newly referred SP cases seen at the outpatient unit of the physiotherapy department, University College Hospital, Ibadan, from January 2006 to December 2010, were identified from the departmental patients' attendance register. Socio-demographic and clinical information were obtained from the case notes and recorded in a self-designed data recording form. These data were then analysed using descriptive statistics of mean, standard deviation and percentage.

The results showed that the cases of SP involved patients between the ages of 13-89 years with a mean age of $53.42 \pm 15.08$ years. Patients in the age group of 60 years and above had the highest prevalence $(35.23 \%)$ of spinal pain. Cases with SP constituted $59.2 \%$ of all the cases managed; and more females $(62.9 \%)$ were reported to have SP. Lumbar spondylosis was the mostly recorded diagnosis while there was no record of coccydynia during the study period. Outcome measures were underutilized with no record of reported outcome measures for the majority of the patients $(51.44 \%)$. Physiotherapists discharge rate of SP was $9.14 \%$.

It can be concluded that SP is a common clinical condition managed in the physiotherapy department of this tertiary health institution, accounting for about $60 \%$ of new patients seen and managed at the orthopaedic unit. It is more common in females than males. Lumbar spondylosis was the most frequently reported diagnosis. Utilization of outcome measures and the discharge pattern of these patients by physiotherapists who managed the patients were poor. This study revealed the need for improvement in clinical documentation of cases, usage of standardized outcome assessment and the need for improvement in the clinical reasoning skills of physiotherapists.
\end{abstract}

KEYWORDS: spinal pain, physiotherapy department, university college hospital, orthopaedic unit, intervention

\section{INTRODUCTION}

Spinal pain is one of the most reported symptoms of musculoskeletal disorders all over the world (Vikat et al, 2000). It affects $70-80 \%$ of adults during their lifetime and its prevalence increases with age (Harreby et al, 1995; Vikat et al, 2000). It is pain that occurs in the vertebral column which may or may not be associated with referred pain. It is usually accompanied by painful limitation of motion and is often as a result of mechanical causes (Kovac et al, 1997). It is also described anatomically as neck pain, upper back pain, coccyx pain (coccydynia), and low back pain (Amal et al, 2007). 
Although many studies have been conducted and published on different types of spinal pain (Duncan, 1981; Postacchini and Massobrio, 1983; Praemer et al, 1992; Atlas, 1996; Argoff et al, 1998; Macllelan et al, 2001; Richard, 2001; Omokhodion and Sanya, 2003; Hodges et al, 2004; Guyatt et al, 2006; Ayanniyi et al, 2010; Pattijn et al, 2010), a search through the literature indicated that studies on the prevalence of spinal pain affecting all the different anatomical locations in a single study among Nigerians are few (Von Koff et al, 2005; Guruje et al, 2007). This study therefore investigated the pattern and profile of new cases of spinal pain seen at the physiotherapy outpatient department of the University College Hospital, Ibadan over a period of five years.

\section{METHODS}

Ethical approval for this study was obtained from the University of Ibadan and University College Hospital Research Ethics Committee. A letter of introduction explaining the nature of the study was written and permission was sought and obtained from the head of the Physiotherapy Department, University College Hospital, Ibadan. Cases of patients with spinal pain who presented at the orthopaedic unit of the physiotherapy outpatient department of the University College Hospital, Ibadan between January 2006 and December 2010 were identified from the departmental patients' attendance register. The referral cards, progress notes and case files of the identified cases were retrieved and sorted. Information on gender, age, primary diagnosis, physiotherapy impression, number of treatment sessions, outcome measures used, physiotherapy intervention, impairment variables, disability variables and discharge rate were then recorded from the referral cards, progress notes and case files in a selfdesigned data recording form. All the new cases referred during the period of the study were also identified. The data obtained was finally entered into a spreadsheet for proper analysis. Descriptive statistics of mean, standard deviation, percentages and frequency distribution were used to summarize the data.

\section{RESULTS}

The total number of newly referred orthopaedic cases seen at the orthopaedic unit of the physiotherapy clinic of the University College Hospital, Ibadan between January 2006 and December 2010 was 1,922. Of these, 1139 (59.26\%) presented with spinal pain (SP). A total of 1053 (92.45\%) of the case files of the SP cases were actually retrieved; the remaining $86(7.55 \%)$ were missing from the outpatient clinic of the Department of Physiotherapy. More female patients $662(62.87 \%)$ than male $391(37.13 \%)$ were reported to have SP. All the patients were newly referred and were attending the orthopaedic outpatient unit of the Department of Physiotherapy, University College Hospital, Ibadan for the first time during the study period. The documented patients were between the ages of 13 and 89 years with a mean and standard deviation of $53.42 \pm 15.08$ years (table 1). The majority of the patients were documented to be aged 60 years and above. The number of treatment sessions recorded ranged from 1-74 with a mean and standard deviation of $9.62 \pm 9.75$ treatment sessions (table 1).

Table 1. Mean age and frequency of treatment for cases with spinal pain by clinical condition

\begin{tabular}{|c|c|c|c|c|}
\hline \multirow[b]{2}{*}{ Clinical condition } & \multicolumn{2}{|c|}{ Ages (in years) } & \multicolumn{2}{|c|}{$\begin{array}{c}\text { No of treatment } \\
\text { sessions }\end{array}$} \\
\hline & Mean & $\begin{array}{l}\text { Standard } \\
\text { deviation }\end{array}$ & Mean & $\begin{array}{r}\text { Standard } \\
\text { deviation }\end{array}$ \\
\hline $\begin{array}{l}\text { Lumbar spondylosis (low } \\
\text { back pain) }\end{array}$ & 55.47 & 13.99 & 11.09 & 11.12 \\
\hline $\begin{array}{l}\text { Cervical spondylosis (neck } \\
\text { pain) }\end{array}$ & 52.35 & 14.95 & 10.02 & 8.94 \\
\hline $\begin{array}{l}\text { Low back pain with SIJ } \\
\text { dysfunction }\end{array}$ & 49.15 & 17.16 & 7.46 & 4.74 \\
\hline $\begin{array}{l}\text { Cervical and Lumbar } \\
\text { spondylosis }\end{array}$ & 56.22 & 14.31 & 9.72 & 7.44 \\
\hline $\begin{array}{l}\text { Thoracic spondylosis } \\
\text { (Upper back pain) }\end{array}$ & 37.71 & 12.22 & 5.71 & 4.86 \\
\hline $\begin{array}{l}\text { Thoraco-lumbar } \\
\text { spondylosis }\end{array}$ & 54.00 & 12.88 & 9.44 & 9.27 \\
\hline $\begin{array}{l}\text { Cervico-thoraco-lumbar } \\
\text { spondylosis }\end{array}$ & 62.00 & 0.00 & 13.00 & 0.00 . \\
\hline Lumbosacral spondylosis & 40.79 & 9.42 & 3.50 & 1.87 \\
\hline Scoliosis & 30.08 & 19.26 & 5.50 & 4.70 \\
\hline $\begin{array}{l}\text { No recorded physiotherapy } \\
\text { impression }\end{array}$ & 52.11 & 15.77 & 7.73 & 8.09 \\
\hline Total & 53.42 & 15.08 & 9.66 & 9.71 \\
\hline
\end{tabular}

The major clinical diagnoses associated with SP were lumbar spondylosis 482 (45.77\%), cervical spondylosis 161 (15.29\%), thoracic spondylosis $7(0.66 \%)$ and scoliosis 12 $(1.14 \%)$. However, some of the patients had more than one 
diagnosis. For instance, $13(1.23 \%)$ were diagnosed with low back pain with sacroiliac dysfunction, $60(5.7 \%)$ had cervical as well as lumbar spondylosis, $16(1.52 \%)$ had thoraco-lumbar spondylosis, and $1(0.09 \%)$ had cervicothoraco-lumbar spondylosis. It is noteworthy that no case of coccydynia was documented for the study period. Also, it was found that $287(26.67 \%)$ of the cases did not have documentation of physiotherapy impressions.

Table 2 shows the trend of referrals of patients with spinal pain yearly. In 2006, there were 204 (19.4\%) cases of spinal pain, whereas as at December 2010, $166(15.8 \%)$ cases of spinal pain were managed at the orthopaedic unit of the physiotherapy clinic. The year 2007 witnessed the highest proportion with $260(24.7 \%)$ spinal pain cases reporting at the outpatient clinic during the study period; the lowest number was recorded in 2010. Throughout the year 2006 , there was no record of any new referral presenting with thoracic pain (upper back pain). However 5 (5\%) cases presented in 2007, which, remarkably, happened to be the year that witnessed the highest number of cases presenting with SP throughout the study period. This reduced to no reported new case $0(0 \%)$ the following year (2008), and subsequently only $1(1 \%)$ case each of thoracic pain was reported in 2009 and 2010.

The only case $(1 \%)$ documented to have simultaneous cervical, thoracic and lumbar pain was at the beginning of the study period (2006). Throughout the study period, new cases of spinal pain were diagnosed by physicians as documented in the referral cards but there was no documentation of physiotherapy impressions. There were only 2 cases of spinal pain with documentation of patientcentred outcome measuring instruments in the management of SP throughout the study period. Only $1(0.10 \%)$ case each was measured using either the McKenzie Institute lumbar spine assessment scale or neck disability index. The other documented outcome measures were impairment measuring instruments. These included the Verbal Rating Scale (VRS), Oxford Muscle Grading Scale (OMGS), Box Numerical Scale (BNS) and Visual Analogue Scale (VAS). The most commonly used outcome measure was the Verbal Rating Scale (VRS) in $13.31 \%$ of cases (figure 1). This was followed by the Oxford Muscle Grading Scale (OMGS) in $13.03 \%$ of cases and the visual analogue scale (VAS) in $10.44 \%$ of cases. The outcome of physiotherapy management in $100(9.58 \%)$ cases was measured using both the OMGS and VRS. The pain rating scale (PRS) and OMGS were co-administered on $11(1.05 \%)$ of the cases of spinal pain while $4(0.38 \%)$ cases were reported to have been evaluated using the box numerical scale (BNS) (figure 1). However, the majority $(51.44 \%)$ of these new cases of spinal pain were not evaluated using any form of outcome measure.

Table 2. The year distribution of the new cases with spinal pain during the 5-year study period

\begin{tabular}{|c|c|c|c|c|c|c|c|c|c|c|c|c|}
\hline & \multicolumn{2}{|c|}{2006} & \multicolumn{2}{|c|}{2007} & \multicolumn{2}{|c|}{2008} & \multicolumn{2}{|c|}{2009} & \multicolumn{2}{|c|}{2010} & \multicolumn{2}{|c|}{ Total } \\
\hline & $\mathrm{n}$ & $\%$ & $\mathrm{n}$ & $\%$ & $\mathrm{n}$ & $\%$ & $\mathrm{n}$ & $\%$ & $\mathrm{n}$ & $\%$ & $\mathrm{n}$ & $\%$ \\
\hline Lumbar spondylosis (low back pain) & 92 & 8.7 & 137 & 13.0 & 78 & 7.4 & 92 & 8.7 & 83 & 7.9 & 482 & 45.8 \\
\hline Cervical spondylosis (neck pain) & 32 & 3.0 & 46 & 4.4 & 22 & 2.1 & 32 & 3.0 & 29 & 2.8 & 161 & 15.3 \\
\hline Low back pain with SIJ dysfunction & 2 & .2 & 3 & .3 & 2 & .2 & 4 & .4 & 2 & .2 & 13 & 1.2 \\
\hline Cervical and lumbar spondylosis & 4 & .4 & 28 & 2.7 & 15 & 1.4 & 9 & .9 & 4 & .4 & 60 & 5.7 \\
\hline Thoracic spondylosis (upper back pain) & 0 & .0 & 5 & .5 & 0 & .0 & 1 & .1 & 1 & .1 & 7 & .7 \\
\hline Thoraco-lumbar spondylosis & 1 & .1 & 7 & .7 & 5 & .5 & 0 & .0 & 3 & .3 & 16 & 1.5 \\
\hline Cervico-thoraco-lumbar spondylosis & 1 & .1 & 0 & .0 & 0 & .0 & 0 & .0 & 0 & .0 & 1 & .1 \\
\hline Lumbosacral spondylosis & 2 & .2 & 1 & .1 & 3 & .3 & 5 & .5 & 3 & .3 & 14 & 1.3 \\
\hline Scoliosis & 6 & .6 & 4 & .4 & 0 & .0 & 1 & .1 & 1 & .1 & 12 & 1.1 \\
\hline No recorded physiotherapy impression & 64 & 6.1 & 29 & 2.8 & 75 & 7.1 & 79 & 7.5 & 40 & 3.8 & 287 & 27.3 \\
\hline Total & 204 & 19.4 & 260 & 24.7 & 200 & 19.0 & 223 & 21.2 & 166 & 15.8 & 1053 & 100.0 \\
\hline
\end{tabular}




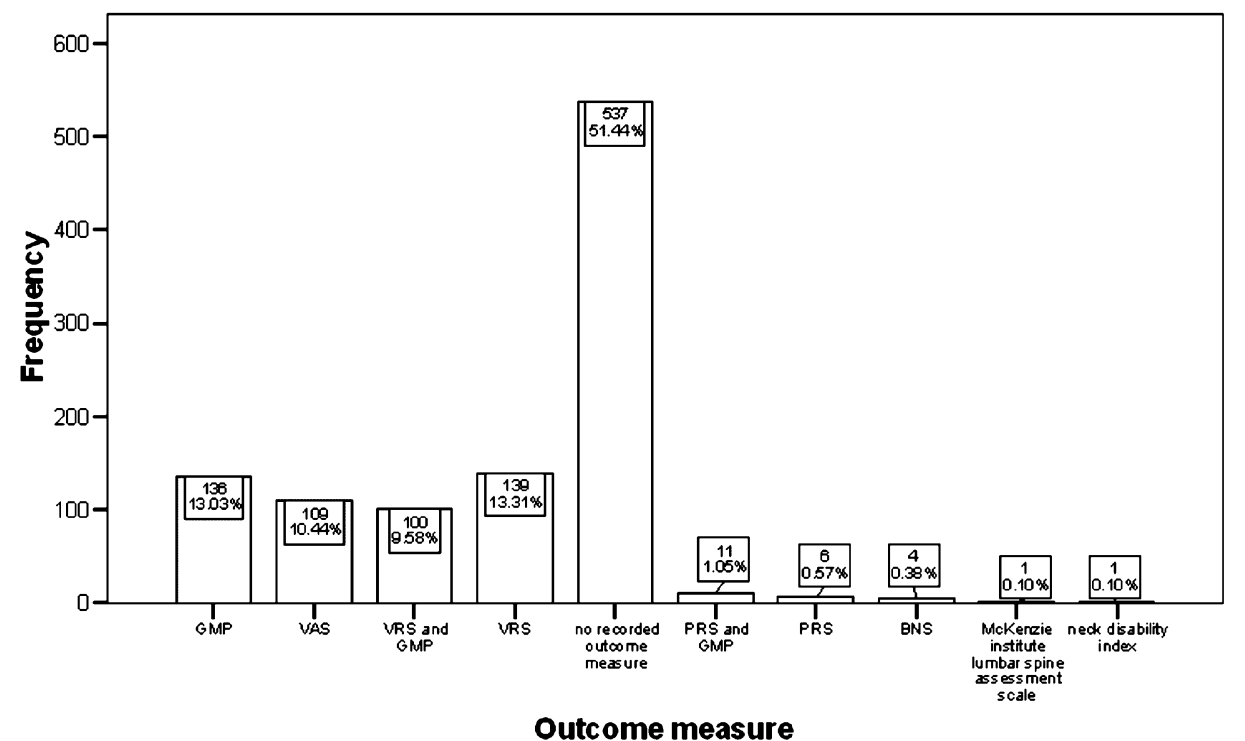

Figure 1. Frequency distribution of outcome measures used in the management of cases with spinal pain during the 5-year study period.

Data obtained from the case notes and files revealed that pain was the major impairment variable $(73.31 \%)$ that was managed by the physiotherapists during the study period. This was followed by muscle weakness. Pain and muscle weakness were discovered to be present in $18.49 \%$ of the new cases seen during the study period, while $8.2 \%$ of the cases presented with pain and muscle spasm.

The results obtained for disability variables assessed in this study showed that $10.9 \%$ of the new cases presented with inability to perform daily activities followed by inability to carry objects. There was no record of specific activities of daily living. Inability to perform sexual activities was documented for $2 \%$ of all the patients. However, the majority $(71.4 \%)$ of the new cases of spinal pain managed were documented with no reported disabilities (table 4). Only a small proportion (9.10\%) of the new cases of spinal pain managed by physiotherapists during the 5-year study period were discharged from the clinic, while only $2.43 \%$ of the cases were referred to other professions. However, the discharge pattern for the majority $(88.6 \%)$ of the cases was not documented.

\section{DISCUSSION}

One thousand, nine hundred and twenty-two newly referred patients with orthopaedic conditions were seen at the orthopaedic unit of physiotherapy clinic at the University
College Hospital, Ibadan between January 2006 and December 2010. Of this number 1,053 case notes were retrieved and reviewed while about 86 could not be retrieved. This may have been as a result of the manual filing system in the physiotherapy department which does not allow for proper record keeping. The finding from this study that more older patients reported with spinal pain suggests that older patients are more predisposed to spinal pain. This observation is supported by the study conducted by Webb et al (2003) in which the authors reported that aging was a strong predictor of cervical intervertebral disc degeneration. The outcome of the present study suggests that women are more predisposed to having spinal pain than men. This is in agreement with the findings of Straker et al (2008) who reported that life prevalence of spinal pain was about $10 \%$ higher $(\mathrm{p}<0.001)$ in females than males.

The anatomical distribution of spinal pain surveyed in this study revealed that low back pain was the most preponderant. This agrees with the report by Richard (1996) in which low back pain was rated as the most prevalent spinal pain condition. There was however, no record of coccydynia throughout the study period. This is partially in harmony with the finding from a previous study conducted on coccydynia (Lyons, 2008) where it accounted for less than $1 \%$ of spinal pain conditions reported to physicians. Upper back pain was identified as the third most 
common spinal pain condition. This is similar to the finding in the study conducted by Van Tulder et al (2006) on the outcome of non-invasive treatment modalities on back pain where upper back pain, also called thoracic pain, was reported as the third most common (22.9\%) after low back and neck pain. It was noted that 2007 witnessed the highest number of new referrals during the study period, out of which low back pain cases predominated. Year 2010 witnessed the lowest number of referrals of spinal pain at the outpatient department. There seems to be no plausible reason for these variations.

Since pain was the major reason why patients seek physiotherapy intervention, pain rating scales were the most administered outcome measures, of which the verbal rating scale (VRS) was reported as the most common. This was followed by visual analogue scale (VAS) when considering pain outcomes. This is in agreement with Cork et al. (2004) who reported that VRS was easier to use than VAS since VRS is not time consuming and does not require any special ability or instrument. This explains why physiotherapists prefer VRS to VAS.

However, the Oxford Muscle Grading System (OMGS) was the second most common outcome used during this study period. No case was recorded to have been assessed using the individual muscle chart. This choice may be explained by the fact that the OMGS is faster and easier to use than the detailed individual muscle charting, especially considering the large number of patients managed by physiotherapists in the orthopaedic unit of physiotherapy departments. As a result of the heavy workload, physiotherapists are often constrained to reduce the assessment time for patients. This practice should however be discouraged; patients can be seen at different times of the day in order to avoid patient overload.

Just two disease-specific outcome measures, namely the McKenzie Institute lumbar spine assessment scale for back pain and neck disability index for neck pain, were reported to have been used during the 5-year study period. In fact, the majority $(51.44 \%)$ did not report using any outcome measure. This may have been due to barriers to their usage. Barriers such as lack of time, resources, and administrative support and low level of familiarity were reported by Emma and Desmond (2008). In a study on familiarity with, knowledge and utilization of standardized outcome measures among physiotherapists in Nigeria conducted by Akinpelu and Eluchie (2006), it was reported that Nigerian physiotherapists' familiarity with, knowledge and use of standardized outcome measures were poor. The utilization of outcome measures by physiotherapists in Nigeria could be stimulated if the Nigeria Society of Physiotherapy organizes series of training workshops on outcome measures for her members.

Pain was reported to be the commonest impairment variable of spinal pain cases and it may or may not be accompanied by other impairment variables. The majority of the cases $(73.31 \%)$ recorded only pain as the impairment variable while the rest were reported to have muscle weakness alongside muscle spasm. Muscle weakness may be a result of a relatively more severe case of nerve compression while muscle spasm could be a result of muscle irritation (Gillead and Brown, 1996).

Disabilities reported in order of their prevalence include: inability to carry objects, inability to walk long distances, inability to sit for long periods, and inability to perform sexual activities. No record of disability status was available for $71.4 \%$ of reviewed cases. It appears that the majority of the treatments administered were targeted at symptom alleviation and eradication. This, however, may not always translate to improvement in disability status (Sullivan et al, 1998).

Results from this study indicate that the physiotherapists did not have the culture of discharging their patients as only about $9 \%$ of cases seen during the study period were formally discharged from treatment. This may be because physiotherapy practice is perceived by physiotherapists as an unending routine and there appears to be no audit of clinical practice. This often results in patients discontinuing treatment of their own volition, probably when they feel they are better or are not responding to treatment. It is necessary that patients are discharged formally when they have a ceiling effect on the improvement of treatment outcomes or they are referred when there is no improvement. The non-utilization of patient-centered measuring instruments as observed in the present study could be a plausible reason for the poor rate of discharge documented in the patients' records. The clinical reasoning skills of physiotherapists can be enhanced when outcome measuring tools are used to promote evidence-based practice as this will help to objectively assess which patients need to be discharged or referred.

This study was limited by information bias characterized by incomplete and improper documentation of patients' case notes, which reduced the volume of clinical information obtainable from the case files. Missing case 
files and progress notes of patients also affected the accuracy of data presented in this study. Hence morbidity rates of spinal pain could not be obtained from this study. However, the outcome of this study is useful for planning towards improvement in record keeping at the physiotherapy department.

\section{References}

Akinpelu, A.O., Eluchie, N.C. 2006. Familiarity with, Knowledge and Utilization of Standardized Outcome Measures among Physiotherapists in Nigeria. Physiotherapy Theory and Practice 22( 2): 61-72.

Amal, M., Deepi, G., Jeffrey, W., Joshua, B., DeAngelis, M., Peter, D., Gus, M.G., Richard, H., David, K., Anita, L., David, M. 2007. Emergency medicine: avoiding the pitfalls and improving the outcomes. Spine 46.

Argoff, C.E., Wheeler, A.H., Backonja, M.M. 1998. Spinal and Radicular Pain Syndromes. Philadelphia, WB Saunders: Neurologic Clinics: 833-845.

Atlas, S.J., Deyo, R.A., Keller, R.B. 1996. The Maine Lumbar Spine Study, II: 1-year outcomes of surgical and nonsurgical management of sciatica. Spine 21: 1777-86.

Ayanniyi, O., Mbada, C.E., Iroko, O.P. 2010. Neck pain occurrence and characteristics in Nigerian university undergraduates. Preventive Medicine Bulletin 9(3):167-174.

Cork, R.C., Isaac, I., Elsharydah, A., Saleemi, S., Zavisca, F., and Alexander, L. 2004. A comparison of the verbal rating scale and the visual analogue scale for pain assessment. The Internet Journal of Anesthesiology 8(1).

Duncan, G. 1981. Painful coccyx. Archives of Surgery 37:1088104.

Gilleard, W.L., Brown, J.M. 1996. Structure and function of the abdominal muscles in primigravid subjects during pregnancy and the immediate post-birth period. Physical Therapy 76(7): 750-761.

Gureje, O., Akinpelu, A.O., Uwakwe, R., Udofia, O., Wakil, A. 2007. Comorbidity and impact of chronic spinal pain in Nigeria. Spine 32(17): E495-500.

Guyatt, G., Gutterman, D., Baumann, M.H., Addrizzo-Harris, D., Hylek, E.M., Phillips, B. 2006. Grading strength of recommendations and quality of evidence in clinical guidelines: report from an American College of Chest Physicians task force. Chest 129(1): 174-81.

Harreby, M., Neergaard, K., Hesselsoe, G. and Kjer, J. 1995. Are radiological changes in the thoracic and lumbar spine of adolescents risk factors for low back pain in adults? A 25-year prospective cohort study of 640 school children. Spine 20: 298-2302.

Hodges, S.D., Eck, J.C., Humphreys, S.C. 2004. A treatment and outcomes analysis of patients with coccydynia. Spine 42: 130140 .
Kovac, F.M., Abraira, V., Pozo, F. 1997. Local and remote sustained trigger point therapy for exacerbations of chronic low back pain: a randomized double-blind controlled multi-center trial. Spine 22:786-789.

Lyons, Michael J. 2008. Coccygodynia. eMedicine. Eds. Daniel Riew, (2008). Medscape.

http://emedicine.medscape.com/article/1264763-overview accessed 01/08/2013, 4.57pm.

Macllelan, L, Suissa, S, Spengler, DM. 2001. Importance and economic burden of occupational back pain: a study of 2,500 cases representative of Quebec. Journal of Occupational Medicine 29(8): 670-4.

Omokhodion, F.O. and Sanya, A.O. 2003. Risk factors for low back pain among office workers in Ibadan, Southwest Nigeria. Journal of Occupational Medicine 53: 287-289.

Pattijn, J., Manssen, M., Hayek, S., Mekhail, N., Zundert, J.V., van Kleef, M. 2010. Coccygodynia. Pain Practice 10: 554559.

Postacchini, F., Massobrio, M. 1983. Idiopathic coccygodynia. Bone Joint Surgery Journal of Amsterdam 65: 1116-24.

Praemer, A., Furner, S., Rice, D. 1992. Musculoskeletal conditions in the United States. Spine 23.

Richard, J. 2001. Spinal endoscopy in chronic low back pain with radiculopathy. A prospective case series. Journal of Anaesthesia 56(5): 454-60.

Stokes, E.K. and O'Neill, D. 2008. Use of outcome measures in physiotherapy practice in Ireland from 1998 to 2003 and comparison to Canadian trends. Canadian Journal of Physiotherapy 60(2): 109-116.

Straker, L.M., O'Sullivan, P.B., Smith, A.J., Perry, M.C., Coleman, J. 2008. Sitting spinal posture in adolescents differs between genders, but is not clearly related to neck/shoulder pain: an observational study. Australian Journal of Physiotherapy 54(2): 127-133.

Sullivan, M.J.L., Stanish W., Waite, H., Sullivan, M.E., Tripp, D. 1998. Catastrophizing, pain, and disability following soft tissue injuries. Pain 77: 253-60.

Van Tulder, M.W., Koes, B.W., Malmivaara, A. 2006. Outcome of noninvasive treatment modalities on back pain: an evidencebased review. Spine 15: 64-81.

Vikat, A., Rimpela, M., Salminen, J.J., Rimpela, A., Savolainen, A., Virtanen, S.M. 2000. Neck or shoulder pain and low back pain in Finnish adolescents. Scandinavian Journal of Public Health 28: 164-173.

Von Koff, M., Crane, P., Lane, M. 2005. Chronic spinal pain and physical-mental comorbidity in the United States: results in national comorbidity survey replication. Pain 115: 331-319.

Webb, R., Brammah, T., Lunt, M., Urwin, M., Alison, T., Symmons, D. 2003. Prevalence and predictors of intense, chronic and disabling neck and back pain in the UK general population Spine 28(11): 1195-202. 